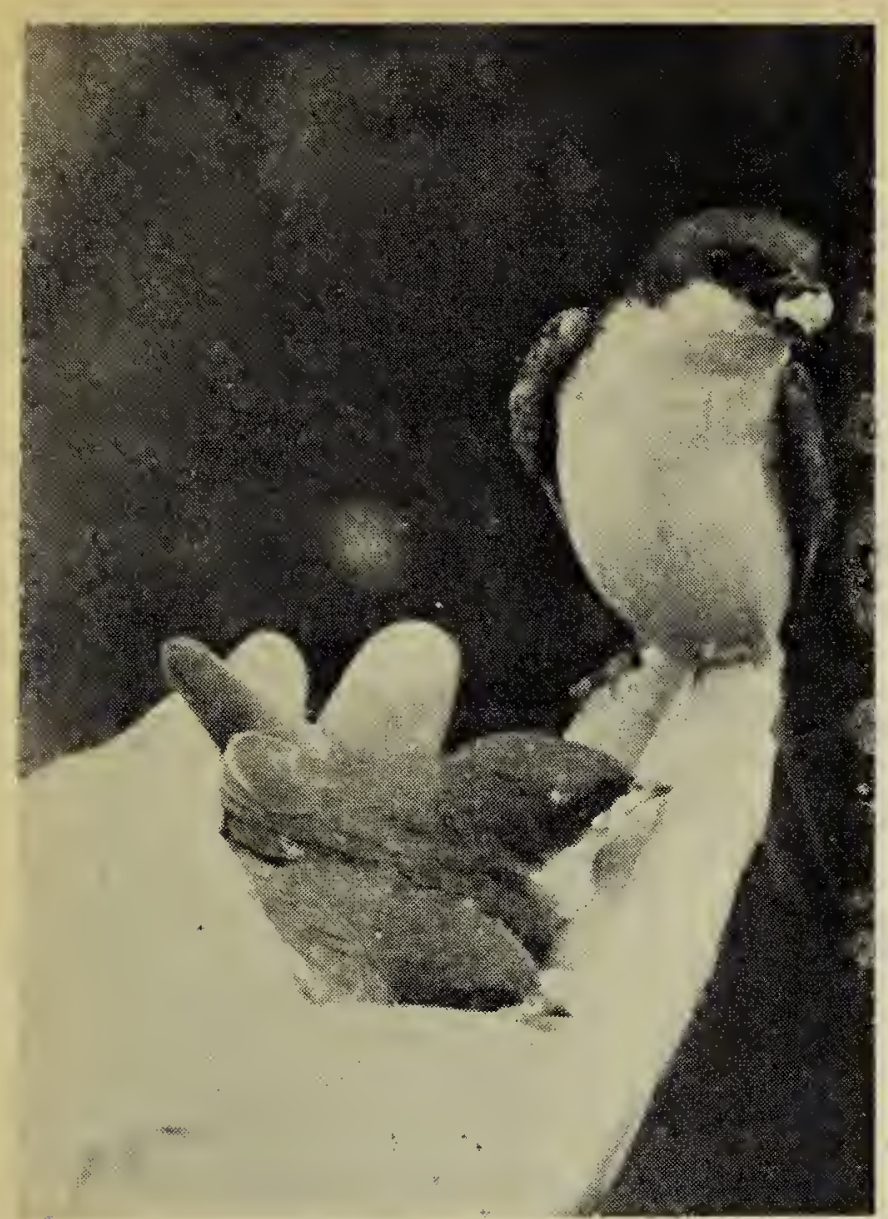

"A bird in the hand

would be nesting along a busy thoroughfare dangerously near the clothes line and almost among the branches of a nearby tree. Yet, like so many people, I simply wanted wild birds in and about my noisy cluttered city yard and I was daring to hope that they would come.

At first the predictions of my friend seemed justified; my nest box attracted only the none-too-particular House Sparrows, which I went out at six o'clock on many a morning to trap in order to discourage them from returning. Then on June 6 , when most swallows were half-way through their nesting season, the first pair of Tree Swallows arrived, and almost immediately set up housekeeping. This they have done annually for the past three years, and as the photos indicate, they have almost accepted us as members of the family.

Obviously the moral of the story is the old one-where there is a will there is a way! The important thing is the will and the patience to execute it. The most difficult for me was to stop thinking about nest boxes and get them up. Nesit boxes should be well ventilated and easily cleaned, and protected from predators such as cats. If you have sparrow trouble, a good idea is to provide a trap door which can be closed behind the unwelcome guests either to keep them out or to remove them from within. A few trappings will generally deter even the most persistent individuals.

\section{TREE SWALLOWS VERSUS HOUSE SPARROWS}

\author{
by David Hatch, Oak Lake
}

During the spring and summer of 1960, I witnessed a struggle between several House Sparrows and Tree Swallows to claim the four nesting boxes around our farm home. House Sparrows, being very plentiful at Oak Lake, are very hard to keep under control. During the first part of the Tree Swallow nesting season, I had to clean each nesiting box daily to remove the nest matierial deposited during the day by House Sparrows.

On one such visit to clean the nesting boxes on May 10, 1960, I was surprised to see upon removing the lid that inside was a live House Sparrow and a dead Tree Swallow. Both were females. The Tree Swallow which could not have been dead more than 30 minutes as it was still quite warm, had been severely picked around both eyes and its beak, the complete area being stained with blood. This swallow, wearing band number 26-84939, had been banded at Oak Lake on July 6,1959 , as a nesting adult female, and had returned safely from its wintering grounds only to be killed by a House Sparrow.

I examined eight Tree Swallow nests in 1960 of which four were presumably destroyed by House Sparrows. The fact that no House Wrens were ever seen at the nesting boxes frees wrens of any responsibility, but in all four nests each egg was punctured or slightly crushed. It didn't appear to matter how far advanced incubation was as the House Sparrows broke the eggs any time from the commencement of egg laying until seven days after incubation started.

At 2.00 p.m. on June 28 , one particular nest contained three eggs and the adult Tree Swallows were in complete command of the nest. Twenty-four hours later all three eggs were broken and I caught a female House Sparrow within the 


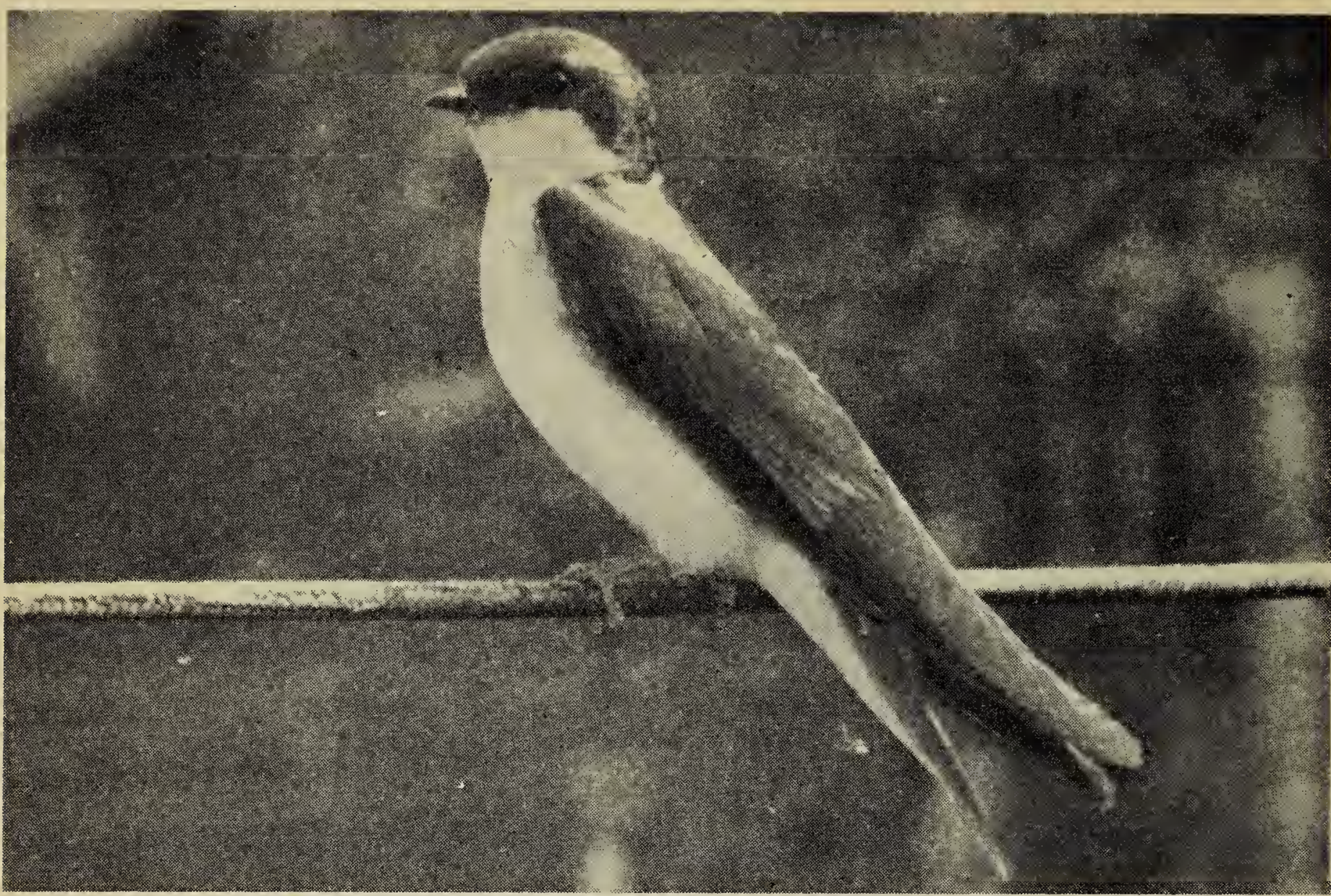

Photo by $R$. W. Fyte

nesting box which already contained a great deal of House Sparrow nesting material. The Tree Swallows immediately left this area.

Another nest, containing seven Tree Swallow eggs, was visited on June 6. Revisiting this nest on June 10, I caught a female House Sparrow in possession and to my surprise the Tree Swallow eggs were replaced by two House Sparrow eggs.

The fact that half of the eight Tree Swallow nests of which I kept records in 1960 were destroyed by House Sparrows shows how destructive the House Sparrow is.

\section{Bank Swallows Nesting in Gravel Stockpiles}

R. W. Nero's note about Bank Swallows nesting in gravel stock-piles (Blue Jay, 19:20-21) reminds me that I saw such in a pile at the Maple River west of Fargo several years ago. In this case I think the pile happened to be undisturbed for a few years. I suspect that one reason that gravel piles are not more commonly used by swallows is that they are heterogeneous. I have often noticed that on banks swallows use tine sandy layers and avoid the more gravelly ones.o. A. Stevens, State University, Fargo, N.D.

Dr. Nero's statement that gravel piles might prove precarious sites for nesiting Bank Swallows (Ibid.) brought to memory an incident which happened in the summer of 1959. While wcrking on a railway gang near Lestock, Saskatchewan, I noticed that Bank Swallows had tunnelled into a highway gravel stock-pile located close to the railway track. I mentioned this to a fellow worker who was also interested in natural history, as he, too, had never seen this type of nesting site before. As our work progressed I wasn't able to observe the colony any further but a few days later my friend told me that while passing by the gravel pile, he actually saw a section of the pile collapse, taking the colony with it. What a sight to see-frantic parents flying in all directions, with a cloud of dust, feathers and nesting material in the air!-Bill Richards, Saskatoon. 